\section{Effects of Plant Growth Regulators on the Endogenous Hormone Content of Calyx Development in 'Korla' Fragrant Pear}

Yan Chen and Min Jin

College of Horticulture and Forestry Science, Tarim University, Alar, Xin Jiang 843300, PR China

Cui-yun Wu and Jian-ping Bao

College of Horticulture and Forestry science, Tarim University, Alar, Xin Jiang 843300, PR China; Xinjiang Production and Construction Corps Key Laboratory of Biological Resources Conservation and Utilization in Tarim Basin, Alar, Xin Jiang 843300, PR China; and National and Local Joint Engineering Laboratory of High-efficiency and High-quality Cultivation and Deep Processing Technology of Characteristic Fruit Trees in Southern Xinjiang, Alar, Xin Jiang 843300, PR China

Additional index words. abscission, calyx, endogenous hormones, pear, persistent

Abstract. The development of calyxes in 'Korla' fragrant pear is influenced by hormones. This study was conducted to investigate the effects of different plant growth regulators on the endogenous hormone content of young 'Korla' fragrant pear fruit. The hormone contents [indoleacetic acid (IAA), gibberellin acid (GA $A_{3}$ ), and abscisic acid (ABA)] of young 'Korla' pear fruits treated with water, IAA, and triiodobenzoic acid (TIBA) were determined by high-performance liquid chromatography, and the relationship between the content and ratio of endogenous hormones and calyx abscission in 'Korla' fragrant pear was explored. The results showed that the rate of calyx abscission in the 'Korla' pear fruits treated with TIBA was significantly higher than that of fruits treated with water and IAA, and that of fruits treated with water was significantly higher than that of fruits treated with IAA. The $\mathbf{G A}_{3}$ content was higher than the IAA and ABA contents during each period. The IAA content of the stalk was higher than that of the calyx tube and flesh. The $G_{3}$ and $A B A$ contents of the calyx tube were higher than those of the stalk and flesh. The IAA and GA 3 contents of the first order were higher than those of the fourth order. The ABA content of the fourth-order fruit was higher than that of the first order. The $\left(\mathrm{IAA}+\mathrm{GA}_{3}\right) / \mathrm{ABA}$ in the calyx tube was significantly higher than that in the flesh and fruit stalk. After IAA treatment, the IAA, $\mathbf{G A}_{3}$, and ABA contents of the first-order calyx tube increased by $47.7 \%, 17 \%$, and $31.6 \%$, respectively, whereas those of the fourth-order calyx tube increased by $65.3 \%, 39.9 \%$, and $33.2 \%$, respectively. After TIBA treatment, the IAA, $\mathrm{GA}_{3}$, and $\mathrm{ABA}$ contents of the first-order calyx tube increased by $46.1 \%, 36.5 \%$, and

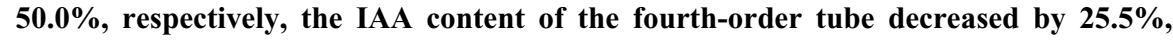
and the $\mathrm{GA}_{3}$ and $\mathrm{ABA}$ contents increased by $22.0 \%$ and $12.2 \%$, respectively. The IAA, $\mathbf{G A}_{3}$, and $A B A$ contents of the flesh and fruit stalk did not significantly differ from those in the calyx tube. The results indicated that spraying IAA during flowering promoted calyx persistence, whereas spraying TIBA promoted calyx abscission. These findings provide certain theoretical references and practical criteria for improving the quality of 'Korla' fragrant pear.

Organ abscission is a physiological phenomenon commonly observed in fruit trees (Shao, 2007), and it is a highly beneficial process for fruit tree evolution. Because of their genetic characteristics, the calyxes of 'Korla' fragrant pears (Pyrus bretschneideri Rehd) persist or fall off, thus forming persistentcalyx or calyx-abscission fruits ( $\mathrm{Li}$ and $\mathrm{He}$, 2008). Persistent-calyx fruit has many quality issues, such as a prominent calyx end, irregular fruit shapes, a large number of stone cells, low sugar content, diminished flavor, and others; however, abscission-calyx fruits have

a regular shape, smooth surface, a small number of stone cells, and a small fruit core. They also have good flavor and are popular with consumers (Qi, 2014). Although the fruit quality can be improved by artificially cutting the calyx, the labor cost is high. After cutting, the calyx end of 'Korla' fragrant pears is scarred, which affects the appearance of the fruit. Therefore, calyx abscission of 'Korla' fragrant pear is beneficial for improving fruit quality and promoting the development of the 'Korla' fragrant pear industry.
Plant organ abscission occurs in the abscissio5n zone, and calyx abscission in 'Korla' fragrant pear fruit is similar to the abscission of other plant organs. A plant organ first occurs in the abscission zone and then falls off ( $\mathrm{Li}$ et al., 2017). Changes in the IAA, GA, and ABA levels are closely related to the formation of abscission zone cells and the abscission of floral organs. IAA is directly related to the formation of the abscission zone and can delay abscission. The degree of its influence on organ abscission is related to concentration, time, and location. ABA can induce the abscission of leaves and floral organs, decrease the transportation of IAA, promote the biosynthesis of ethylene, and indirectly promote the abscission of plant organs. The various endogenous hormones in the flowering stage of 'Korla' fragrant pears are mutually regulated, and their distribution in different parts of the flowering stage can have a key role in calyx abscission.

Plant growth regulators are synthetic chemical components, such as IAA, naphthalene acetic acid, ethephon, paclobutrazol, and TIBA, that can effectively control the growth and development of plants (Jin, 2020). Gao et al. (1999) reported that spraying a certain concentration of paclobutrazol $\left(\mathrm{PP}_{333}\right)$ during flowering can increase the sepal shedding rate of 'Dangshansuli' and 'Korla' fragrant pear. Li et al. (2001) stated that the application of $2000 \mathrm{mg} \cdot \mathrm{L}^{-1}$ of paclobutrazol can significantly increase the calyx removal rate of fragrant pears by almost $25 \%$ to $70 \%$. Previous studies demonstrated that IAA can reduce the sensitivity of cells in the isolated zone to ethylene and inhibit the shedding of plant organs (Han, 2018). Both TIBA and $\mathrm{PP}_{333}$ are growth regulators that inhibit the polar transport of auxin and weaken its effect and inhibit plant top growth (Gong et al., 2019). Therefore, in this study, 'Korla' fragrant pear was used as the test material. Plant growth regulators IAA and TIBA were sprayed during the flowering period to determine the changes in the contents of IAA, $\mathrm{GA}_{3}$, and $\mathrm{ABA}$ in the calyx tube, flesh, and stalk of 'Korla' fragrant pear during the sepal shedding period. The relationship between various endogenous hormones and their interactions and sepal shedding of 'Korla' fragrant pear fruit was discussed to provide a reference for solving the problem of pear fruit sepal persistence in production.

\section{Materials and Methods}

Test location and materials. The test materials for this experiment were 22-year-old 'Korla' fragrant pears provided by the pear germplasm resource nursery in Tarim University. Varieties with consistent tree vigor, consistent irrigation methods, and consistent soil types from the same plot were selected, and Pyrus betulaefolia Bge. was used as the rootstock. 
Material collection. In the large flower bud stage, 30 'Korla' fragrant pear trees with relatively consistent growth conditions were selected as sample plants, and the flower numbers on short fruiting branches on the western outer edge of the canopy were listed. Ten trees were sprayed with water as a control, 10 were sprayed with $100 \mathrm{mg} / \mathrm{L}$ of IAA, and 10 were sprayed with $100 \mathrm{mg} / \mathrm{L}$ of TIBA. Persistentcalyx fruit were treated with IAA, whereas calyx-abscission fruit were treated with TIBA. Samples were collected every $3 \mathrm{~d}$ at the beginning of the large flower bud stage (2 Apr. 2020), and young fruit were collected six times until stable (17 Apr. 2020). Samples were covered throughout the whole 'Korla' fragrant pear calyx abscission period. According to the investigation, the percentage of persistent calyx fruit in the first order of 'Korla' fragrant pear trees was almost $70 \%$, and the percentage of abscission calyx fruit in the fourth order was almost $80 \%$ (Zhou et al., 2018). Therefore, first-order fruit were regarded as persistent-calyx fruit, and fourth-order fruit were used as abscission-calyx fruit. Thirty corymbose orders were collected in the natural state, and the first-order (Fig. 1) fruit with a higher percentage of persistent calyxes and fourth-order fruit with a higher percentage of calyx abscission were collected. Additionally, 30 orders treated with IAA and TIBA were picked. The samples were placed in an icebox and transported to a laboratory for deionization. After cleaning the flowers with deionized water, the separated parts of the fruit calyx tube, flesh, and stalk (Fig. 1) were obtained, cooled with liquid nitrogen, and placed in a refrigerator at $-80^{\circ} \mathrm{C}$ to determine the IAA, $\mathrm{GA}_{3}$, and $\mathrm{ABA}$ contents.

Calyx-abscission fruit investigation rate. Twenty days after flowering, the calyx-abscission rates of the first-order and fourth-order Korla pear fruits treated with water (control),

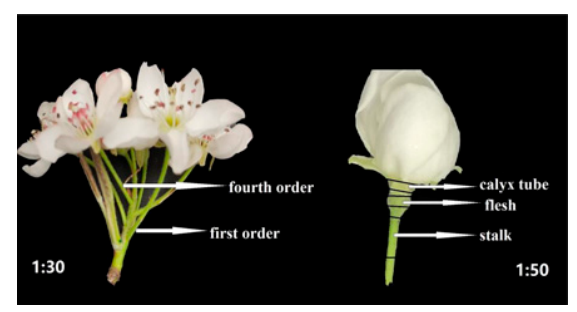

Fig. 1. First-order, fourth-order, calyx tube, flesh, and stalk of 'Korla' fragrant pear.

Received for publication 30 Nov. 2021. Accepted for publication 4 Jan. 2022.

Published online 21 February 2022.

This study was supported by the Major Science and Technology Project of Xinjiang Production and Construction Corps (2017DB006-3), the National Natural Science Foundation of China (31860528, U2003121).

We thank Editage (www.Editage.com) for providing linguistic assistance during the preparation of this article.

J.-P.B. is the corresponding author. E-mail: baobao-xinjiang@126.com.

This is an open access article distributed under the CC BY-NC-ND license (https://creativecommons. org/licenses/by-nc-nd/4.0/).
IAA, and TIBA were determined as follows:

Rate of calyx-abscission fruit $(\%)=$

calyx-abscission fruit/total number of fruits $\times 100 \%$.

Determination of endogenous hormones. A 1260 HPLC instrument (equipped with a G1311C quaternary pump, G13-29B automatic temperature control autosampler, G1316A column thermostat, G4260B ELSD, and Open LABORATORY CDS chromatographic workstation) purchased from Agilent (Palo Alto, $\mathrm{CA})$ was used for endogenous hormone determination. Standard RE3000IAA, GA, and ABA products from Sigma (NASDAQ, CA), chromatographic methanol from TEDIA, chromatography-grade formic acid, and ultrapure water were all used. The chromatographic column was an Agilent Zorbax SBC18 $(4.6 \times 150 \mathrm{~mm} ; 3.5 \mu \mathrm{m})$ with a column temperature of $30^{\circ} \mathrm{C}$; methanol, $0.1 \%$ formic acid mixture, and $0.1 \%$ formic acid aqueous solution were used as the mobile phase, the flow rate was $0.4 \mathrm{~mL} \cdot \mathrm{min}^{-1}$, the detection wavelength was $255 \mathrm{~nm}$, and the injection volume was $10 \mu \mathrm{L}$.

A 1-g sample was ground with $10 \mathrm{~mL}$ of isopropanol hydrochloric acid buffer $(\mathrm{pH}=$ 2.2; isopropanol: $\mathrm{ddH}_{2} \mathrm{O}$ :concentrated hydrochloric acid $=200 \mathrm{~mL}: 100 \mathrm{~mL}: 200 \mu \mathrm{L}$ ) in a weak light ice bath. Samples were placed in a $4{ }^{\circ} \mathrm{C}$ water bath and shaken for $30 \mathrm{~min}$. Then, $20 \mathrm{~mL}$ of dichloromethane was added. The samples were then placed in a $4{ }^{\circ} \mathrm{C}$ water bath and shaken for $30 \mathrm{~min}$. Then, they were centrifuged for $10 \mathrm{~min}$ at $4{ }^{\circ} \mathrm{C}$ and $5000 \mathrm{r}$. The organic phase of the lower layer was removed and dried with nitrogen in dark. The sample was dissolved in a mixture containing $2 \mathrm{~mL}$ of methanol and $0.1 \%$ formic acid, passed through a $0.22-\mu \mathrm{m}$ organic filter membrane, and stored at $-20^{\circ} \mathrm{C}$ for highperformance liquid chromatography (HPLC) analysis and determination (Duan et al., 2015).

Statistical analysis. Three biological replicates were used for all experiments, and the results were expressed as the mean and SE of experiments conducted in triplicate. Data processing and statistical analyses were conducted using Excel 2010 and SPSS 18.0 (version 18.0; IBM Corp., Armonk, NY). GraphPad Prism 8.0.2 was used to draw the graphs (version 8.0.2; GraphPad Corp., San Diego, CA).

\section{Results}

Effects of different treatments on the calyx abscission of 'Korla' fragrant pear

After treating 'Korla' fragrant pears with water, IAA, and TIBA, the calyx abscission rate decreased in the following order: TIBA treatment $>$ control $>$ IAA treatment (Fig. 2). The calyx abscission rate of 'Korla' fragrant pears after TIBA treatment was significantly higher than those after the water and IAA treatments. The calyx abscission rates of the firstorder fruits were $56.7 \%, 21.7 \%$, and $85.3 \%$, and those of the fourth-order fruits were $71.3 \%, 26.7 \%$, and $90.0 \%$, respectively. Under

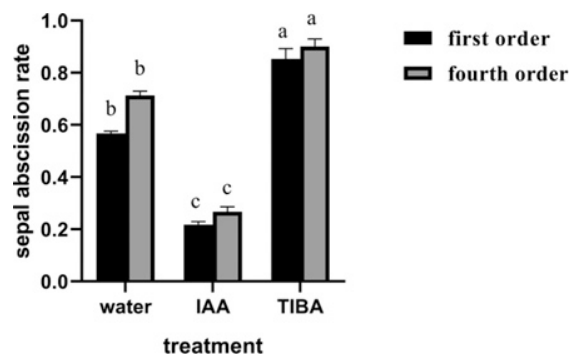

Fig. 2. Effects of different treatments on calyx abscission of 'Korla' fragrant pear. Significant differences between first order and fourth order at $P<0.05$ are represented by letters $\mathrm{a}, \mathrm{b}$, and $\mathrm{c}$.

the same treatment, the calyx abscission rate of the fourth-order 'Korla' fragrant pears was higher than that of the first-order pears. The results indicated that spraying IAA during flowering inhibited calyx abscission, whereas spraying TIBA promoted calyx abscission.

\section{Effects of different treatments on} endogenous hormones in the calyx tube of 'Korla' fragrant pear during development

Changes in the IAA content of different parts of 'Korla' fragrant pear during calyx development. The IAA contents of the calyx tube (Fig. 3A) and flesh (Fig. 3B) of the firstand fourth-order 'Korla' fragrant pears were highest on 14 Apr. The content of the firstorder calyx tube was significantly higher than that of the fourth-order tube. There were no significant differences in the IAA contents of the first- and fourth-order flesh, and the IAA content of the flesh of 'Korla' fragrant pears (Fig. 3B) was significantly lower than that of the other two parts. The IAA content of the stalks of 'Korla' fragrant pears (Fig. 3C) gradually increased. From 8 to $17 \mathrm{Apr}$., the IAA content gradually reached the maximum, and the difference was significant.

After IAA treatment, there was no significant change in the IAA content from 2 to 8 Apr.; after 8 Apr., the IAA content of the first- and fourth-order calyx tubes began to increase significantly and reached the maximum value on 14 Apr. before decreasing. On 17 Apr., the IAA content of the fourth-order calyx tubes was greater than that of the firstorder calyx tubes. The IAA content of the IAA treatment was higher than that of the water treatment (Fig. 4A). The content of the flesh exhibited an upward decreasing trend, and there was no significant change with IAA treatment (Fig. 4B). The content of the fruit stalk was significantly different after IAA treatment, particularly from 8 to 14 Apr., during which the IAA content of the fourth-order stalks was significantly higher than that of the first-order stalks, indicating that IAA treatment significantly affected the IAA content of the calyx tube and fruit stalk (Fig. 4C).

After TIBA treatment, the IAA content of the calyx tube (Fig. 5A) of first-order 'Korla' fragrant pear was higher than that of fourth- 

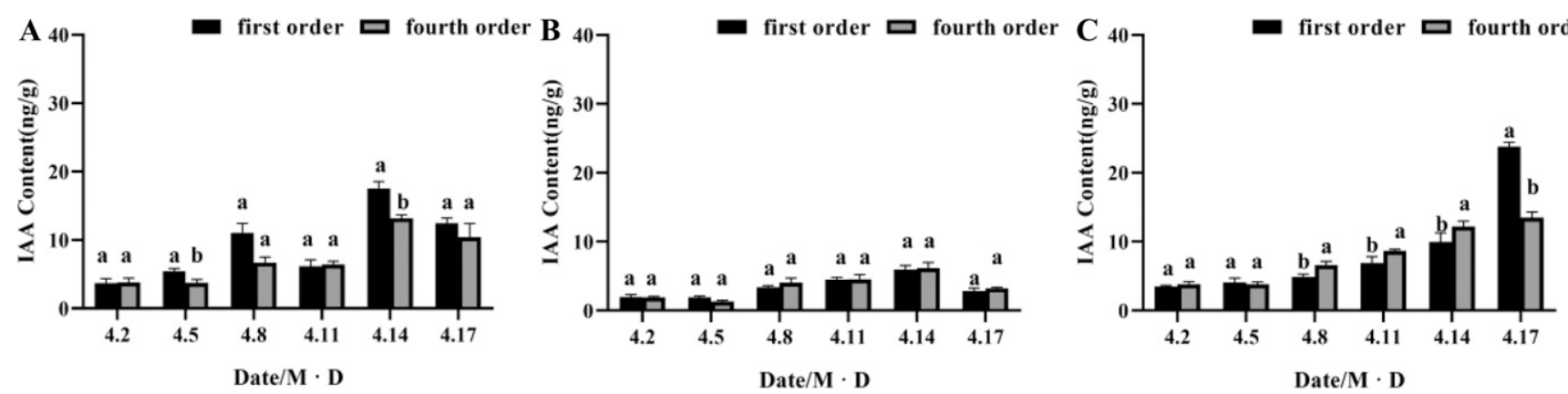

Fig. 3. Changes in the indoleacetic acid (IAA) contents of the calyx tube (A), flesh (B), and stalk (C) of 'Korla' fragrant pears treated with water.

order fruits; the change was significant from 14 to 17 Apr., and it peaked on 14 Apr. The variation in the IAA content of the flesh (Fig. 5B) was low during calyx abscission. That of the first-order fruits was slightly larger than that of the fourth-order fruits during the early stage, whereas that of the fourth-order fruits gradually became larger than that of the first-order fruits during the late stage. The IAA content of the flesh was significantly lower than that of the calyx tubes and fruit stalks. The overall difference was not significant in the first-order fruits; however, the IAA content of the flesh was significantly lower than that of the calyx tubes and fruit stalks from 14 to $17 \mathrm{Apr}$. The IAA content of the fruit stalks (Fig. 5C) exhibited an upward decreasing and increasing trend. Excluding 8 Apr., the IAA content of the first-order fruits was higher than that of the fourth-order fruits stalk. The content of the fourth-order fruits stalk was slightly higher than that of the first-order fruits, with no significant difference.
Effects of different treatments on the $\mathrm{GA}_{3}$ content in different parts of 'Korla' fragrant pears during calyx development. As shown in Fig. 6A, the $\mathrm{GA}_{3}$ content of the calyx tube in the first- and fourth-order 'Korla' fragrant pears gradually increased until it peaked on 8 Apr.; thereafter, it decreased. After 14 Apr., the $\mathrm{GA}_{3}$ content followed a decreasing trend, and the overall change was clear. In the flesh of first- and fourthorder 'Korla' fragrant pears, the $\mathrm{GA}_{3}$ contents first slowly decreased, then slightly increased, and finally slightly decreased (Fig. 6B). The overall change and difference were not significant. During the early stage, the $\mathrm{GA}_{3}$ content of first-order 'Korla' fragrant pears was greater than that of the fourth-order pears. However, during the later stage, the $\mathrm{GA}_{3}$ content of the fourthorder pears was greater than that of the first-order pears (Fig. 6C). The $\mathrm{GA}_{3}$ content of the calyx tube was significantly higher than that of the flesh and fruit stalk. The
$\mathrm{GA}_{3}$ contents of the calyx tube and stalk of the first-order fruits were significantly greater than those of the fourth-order fruits, particularly in the calyx tube, whereas the content of the flesh of fourth-order fruits was higher than that of first-order fruits.

After IAA treatment, the $\mathrm{GA}_{3}$ content of the calyx tube of first- and fourth-order fruits increased significantly from 2 to $11 \mathrm{Apr}$., and it decreased significantly from 11 to 17 Apr., peaking on 11 Apr. Excluding the insignificant difference between 2 and 5 Apr., the $\mathrm{GA}_{3}$ content of the first-order fruits that received IAA treatment was significantly higher than the content of those that received water treatment (Fig. 7A). On 2, 8, 14, and 17 Apr., the $\mathrm{GA}_{3}$ content of the fourth-order fruits was slightly higher than that of the first-order fruits, whereas that of the firstorder fruits was slightly higher than that of the fourth-order fruits on 5 and $11 \mathrm{Apr}$. There was no significant difference in the $\mathrm{GA}_{3}$ content of the flesh of the first- and fourth-order
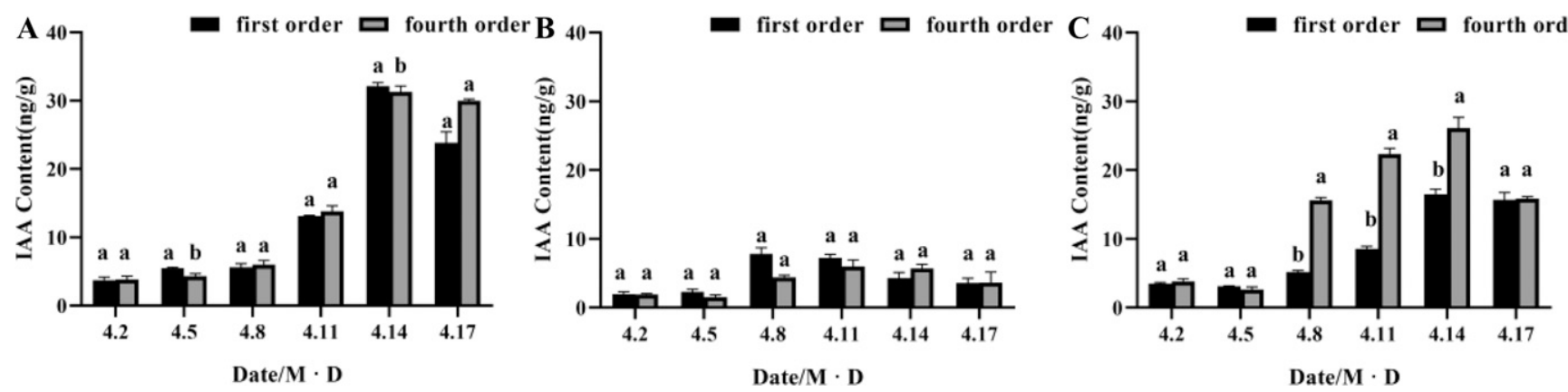

Fig. 4. Changes in the indoleacetic acid (IAA) contents of the calyx tube (A), flesh (B), and stalk (C) of 'Korla' fragrant pears with the IAA treatment.
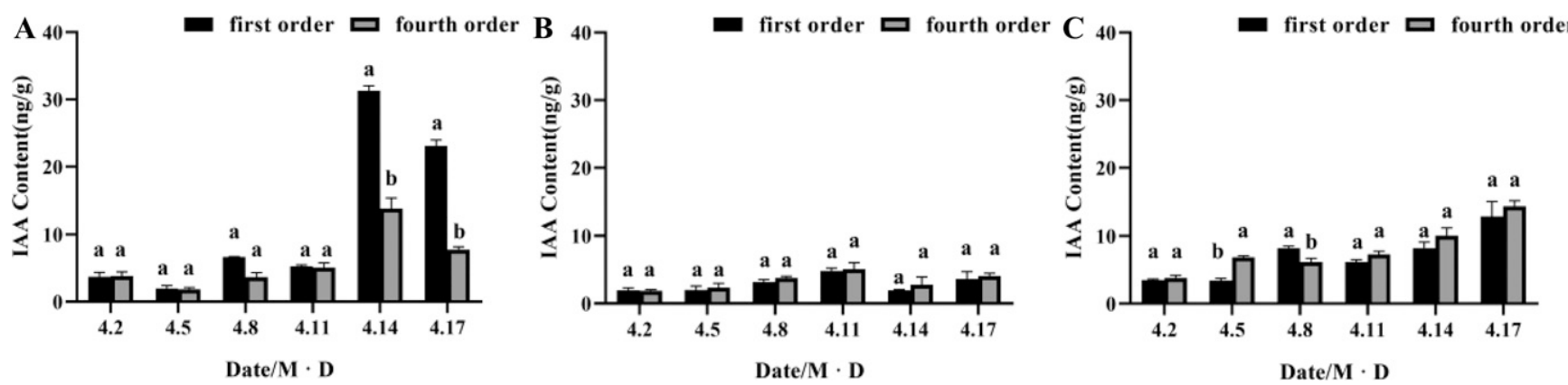

Fig. 5. Changes in the indoleacetic acid (IAA) contents of the calyx tube (A), flesh (B), and stalk (C) of 'Korla' fragrant pears with triiodobenzoic acid treatment. 

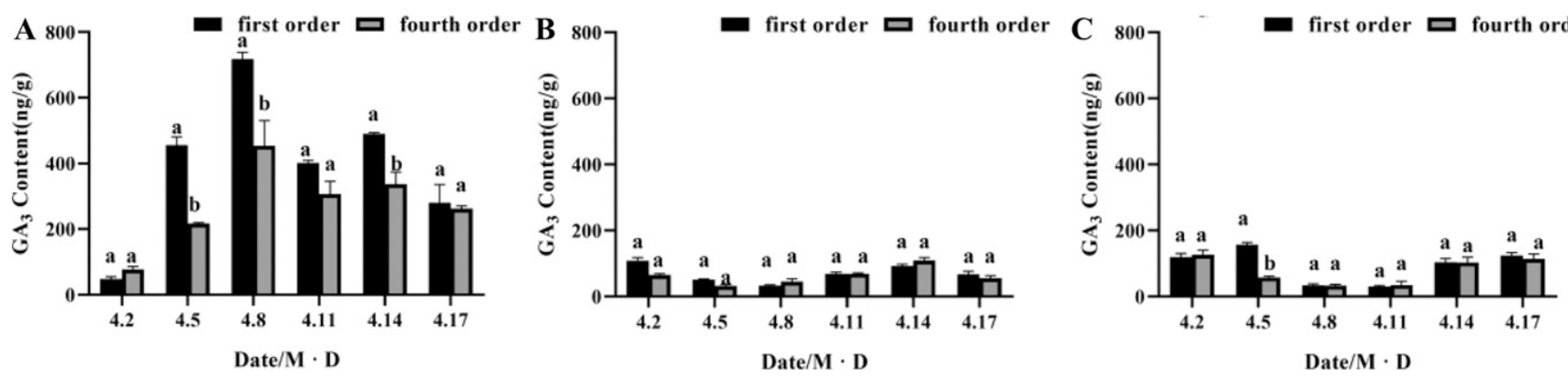

Fig. 6. Changes in the gibberellin acid $\left(\mathrm{GA}_{3}\right)$ contents of the calyx tube $(\mathbf{A})$, flesh $(\mathrm{B})$, and stalk $(\mathbf{C})$ of 'Korla' fragrant pears treated with water.

fruits. The $\mathrm{GA}_{3}$ content was reduced to the lowest level from 5 to $8 \mathrm{Apr}$., and it was less than $120 \mathrm{ng} / \mathrm{g}$ during all periods (Fig. 7B). Additionally, the differences in the $\mathrm{GA}_{3}$ content of the fruit stalks were not significant (Fig. 7C).

The $\mathrm{GA}_{3}$ content of the calyx tube was highest on 18 Apr., and the difference between the first- and fourth-order fruits was significant (Fig. 8A). The $\mathrm{GA}_{3}$ contents of both the flesh (Fig. 8B) and fruit stalk (Fig. $8 \mathrm{C})$ were low, and there was no significant difference between the first- and fourth-order fruits.

Effects of different treatments on the $A B A$ content in different parts of 'Korla' fragrant pear during calyx development. There was no significant difference in the ABA content of the first- and fourth-order fruits on 2 and 8 Apr. On 5 and 14 Apr., the ABA content of the first-order fruits was significantly higher than that of the fourth-order fruits. In contrast, on 11 and 17 Apr., the ABA content of the first-order fruits was lower than that of the fourth-order fruits (Fig. 9A). The ABA content of the flesh of first-order fruits was higher than that of the fourth-order fruits, except on 5 and 11 Apr., and the content of the flesh of fourth-order fruits exceeded that of the flesh of the first-order fruits at other times (Fig. 9B). The change trends of the first- and fourth-order fruit stalks were similar. According to the experimental results, the ABA contents of the fourthorder calyx tube, flesh, and fruit stalk were higher than those of the first-order fruits on 17 Apr., indicating that it was easier for calyxes to fall off at higher ABA contents (Fig. 9C).

The ABA content increased significantly after IAA treatment. On 2 Apr., the ABA content in the first-order calyx tube was the same as that in the fourth-order calyx tube. On 5 Apr., the ABA content of the first-order calyx tube was higher than that of the fourth-order calyx tube, whereas the opposite was true after 8 Apr. (Fig. 10A). The difference between the first- and fourth-order fruits was not significant after 5 Apr. (Fig. 10B). The change trends of the fruit stalk ABA contents of the first- and fourth-order pears were similar, and they only significantly differed on 5 and 14 Apr. (Fig. 10C).

There was no difference in the ABA contents of the calyx tubes of the first- and fourth-order fruits on 2 Apr.; however, the ABA content of the first-order tubes then increased, peaking on 17 Apr., whereas that of the fourth-order tubes began to increase on $5 \mathrm{Apr}$. and peaked on $11 \mathrm{Apr}$. before gradually decreasing. The ABA content of the fourth-order fruits was significantly lower than that of the first-order fruits on 17 Apr. (Fig. 11A), when the ABA content of the first-order flesh was higher than that of the fourth-order flesh, whereas the contents were the same on the other dates.
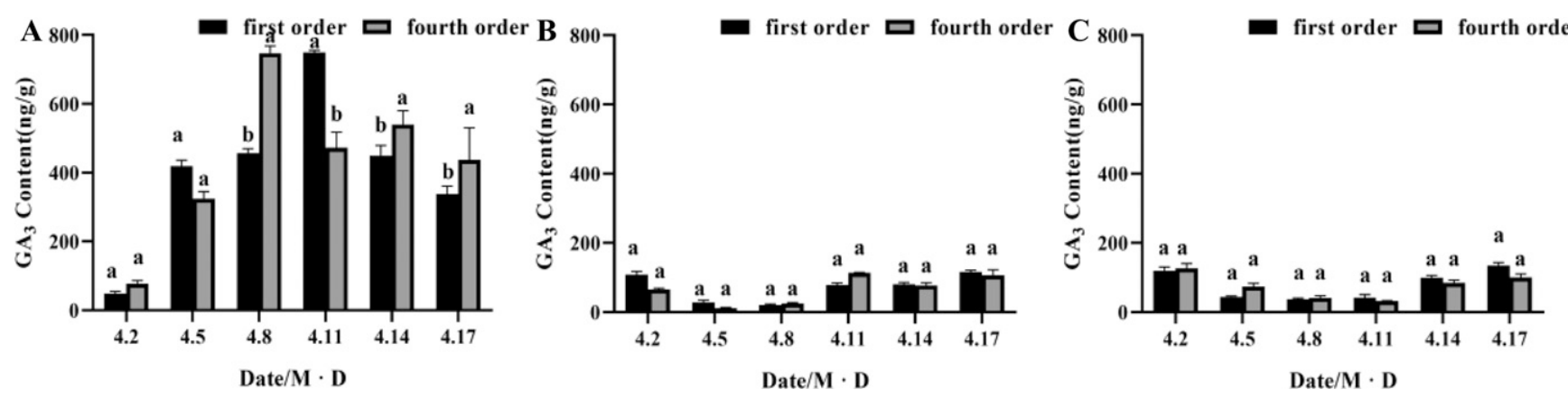

Fig. 7. Changes in the gibberellin acid $\left(\mathrm{GA}_{3}\right)$ contents of the calyx tube $(\mathbf{A})$, flesh $(\mathbf{B})$, and stalk $(\mathbf{C})$ of 'Korla' fragrant pear treated with indoleacetic acid.
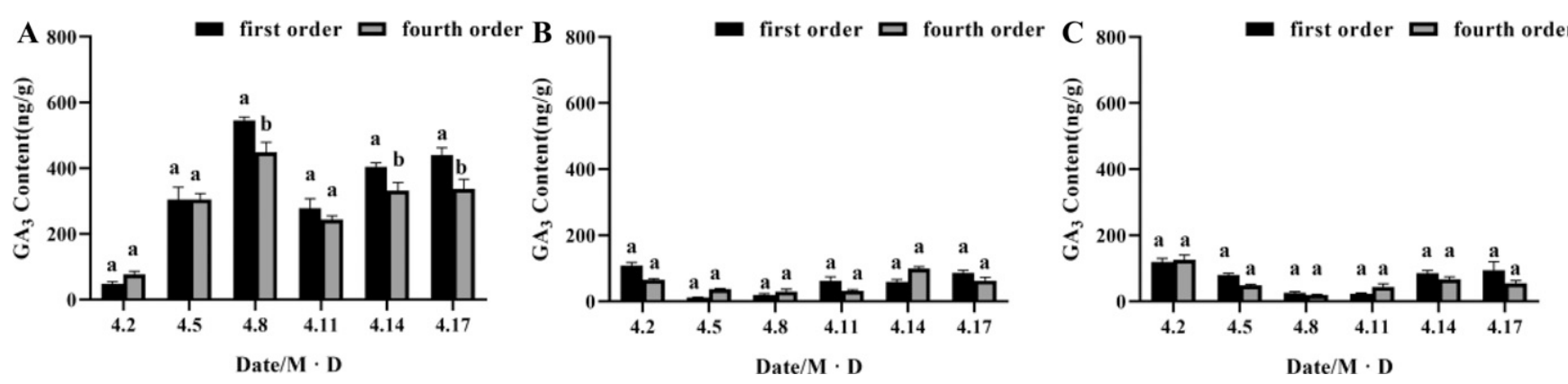

Fig. 8. Changes in the gibberellin acid $\left(\mathrm{GA}_{3}\right)$ contents of the calyx tube $(\mathbf{A})$, flesh $(\mathbf{B})$, and stalk $(\mathbf{C})$ of 'Korla' fragrant pear treated with triiodobenzoic acid. 

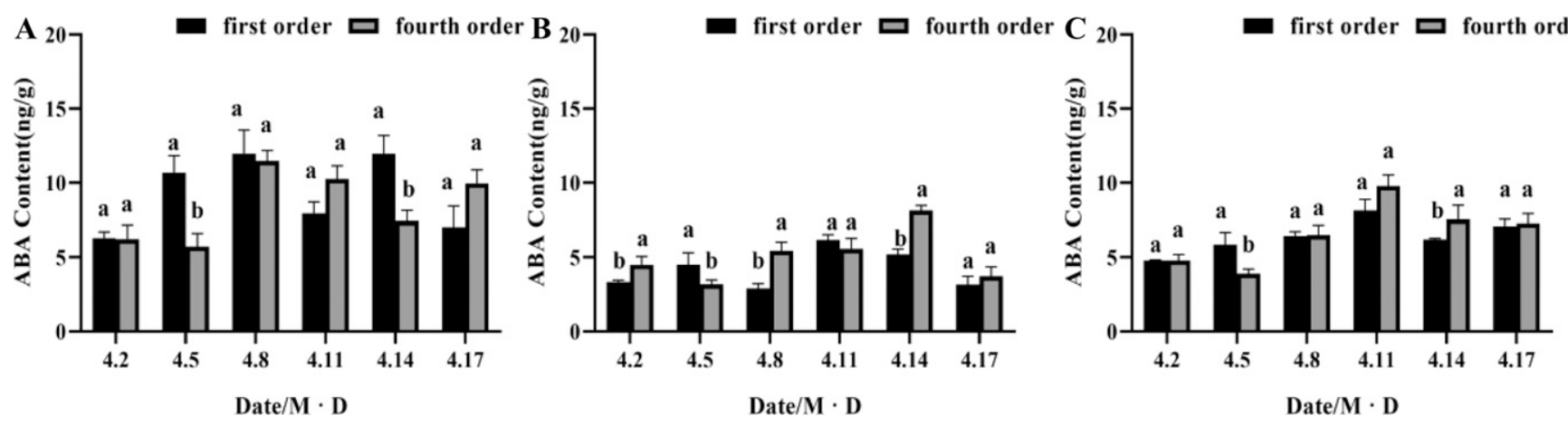

Fig. 9. Changes in the abscisic acid (ABA) contents of the calyx tube (A), flesh (B), and stalk $(\mathbf{C})$ of 'Korla' fragrant pears treated with water.

Effects of different treatments on the ratio of $\left(I A A+G A_{3}\right) / A B A$ in the calyx tube of 'Korla' fragrant pears. The ratios of (IAA $\left.+\mathrm{GA}_{3}\right) /$ ABA of the calyx tube of first-order 'Korla' fragrant pears under water and IAA treatments first increased and then decreased with a wide range, peaking on 11 Apr. There was no significant difference in the ratio of $\left(\mathrm{IAA}+\mathrm{GA}_{3}\right) /$ ABA of the calyx tube of first-order 'Korla' fragrant pears among the water, IAA, and TIBA treatments on $17 \mathrm{Apr}$. Additionally, the $\left(\mathrm{IAA}+\mathrm{GA}_{3}\right) / \mathrm{ABA}$ change trend in the calyx tube of fourth-order 'Korla' fragrant pears was similar between the water and IAA treatments, and the range was small. Before 11 Apr., the $\left(\mathrm{IAA}+\mathrm{GA}_{3}\right) / \mathrm{ABA}$ ratio of the calyx tube of fourth-order 'Korla' fragrant pears under the TIBA treatment was significantly higher than that under the water and IAA treatments, whereas it was significantly lower after 11 Apr. (Fig. 12); then, it became similar among the three treatments on 17 Apr. (Fig. 12A).
Effects of different treatments on the flesh $(I A A+G A 3) / A B A$ ratio of 'Korla' fragrant pear. The ratios of $\left(\mathrm{IAA}+\mathrm{GA}_{3}\right) / \mathrm{ABA}$ in the flesh of first- and fourth-order 'Korla' fragrant pears were low and changed similarly without significant differences. The $\left(\mathrm{IAA}+\mathrm{GA}_{3}\right) / \mathrm{ABA}$ ratio of the first-order fruit did not exceed 40.00 , whereas that of the fourth-order fruit did not exceed 30.00. The ratio of the first-order fruits was slightly higher than that of the fourth-order fruits, and the difference between different treatments was not notable. The ratio of the firstand fourth-order fruits peaked on 2 and 17 Apr., respectively (Fig. 13A).

Effects of different treatments on the $\left(I A A+G A_{3}\right) / A B A$ value of 'Korla' fragrant pear stalks. The $\left(\mathrm{IAA}+\mathrm{GA}_{3}\right) / \mathrm{ABA}$ ratios of the stalks of first-order 'Korla' fragrant pears treated with water, IAA, and TIBA were all low, and the difference was not significant. From 2 to 8 Apr., the ratio of (IAA $+\mathrm{GA}_{3}$ )/ ABA for the stalks of first-order pears increased slightly and then decreased, and it was higher than that of the IAA and TIBA treatments. Under the TIBA treatment, the ratio exhibited a slow and decreasing trend. After 8 Apr., the (IAA $\left.+\mathrm{GA}_{3}\right) / \mathrm{ABA}$ ratio of the stalks of first-order pears gradually increased with the water, IAA, and TIBA treatments. The variation in the (IAA $\left.+\mathrm{GA}_{3}\right) /$ $\mathrm{ABA}$ ratio of the stalks of fourth-order 'Korla' fragrant pears treated with IAA was consistent with that observed with TIBA treatment, whereas that observed with the water treatment peaked on $8 \mathrm{Apr}$. and was significantly higher than that observed with the IAA and TIBA treatments (Fig. 14A).

\section{Discussion}

Phytohormones are synthesized in plants, can move freely, and produce trace organic substances that significantly affect growth and development (Chen, 2011). The regulation of
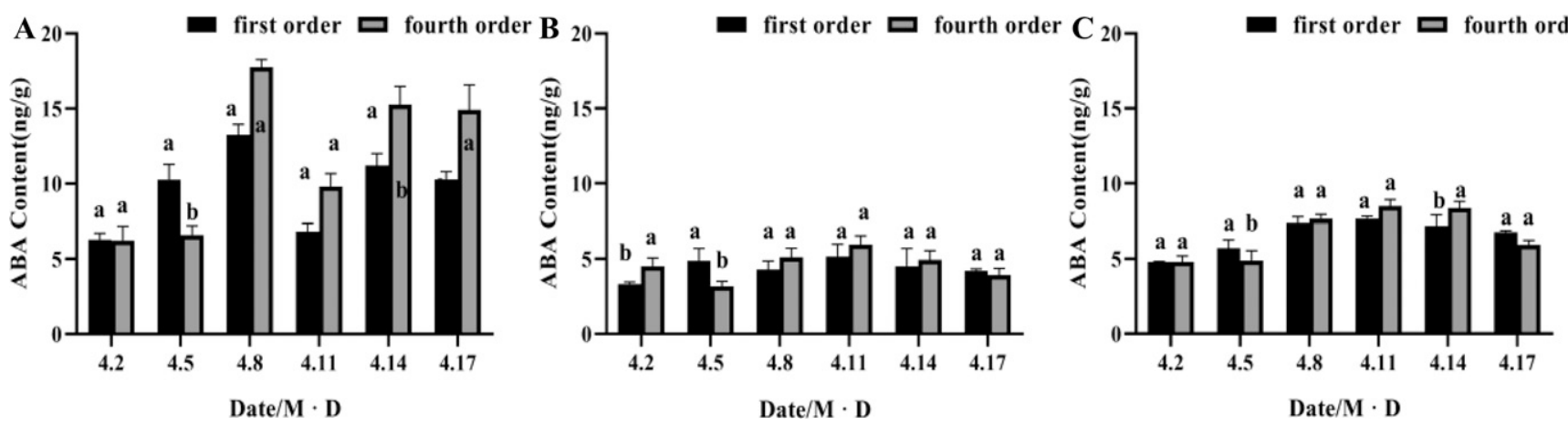

Fig. 10. Changes in the abscisic acid (ABA) contents of the calyx tube (A), flesh (B), and stalk (C) of 'Korla' fragrant pears treated with indoleacetic acid.
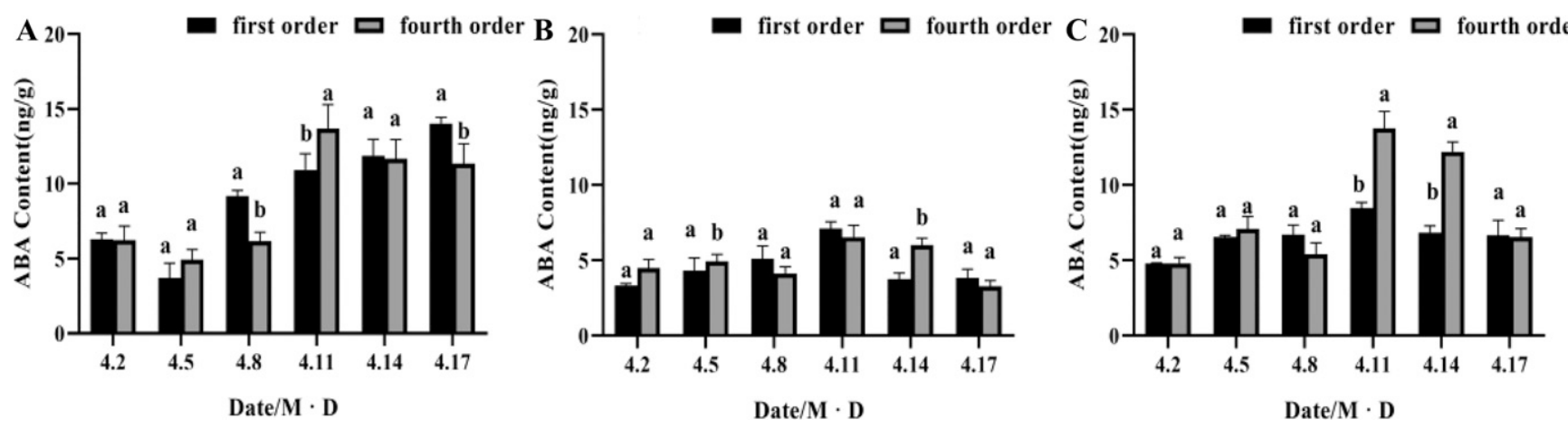

Fig. 11. Changes in the abscisic acid (ABA) contents of the calyx tube (A), flesh (B), and stalk (C) of 'Korla' fragrant pears treated with triiodobenzoic acid. 

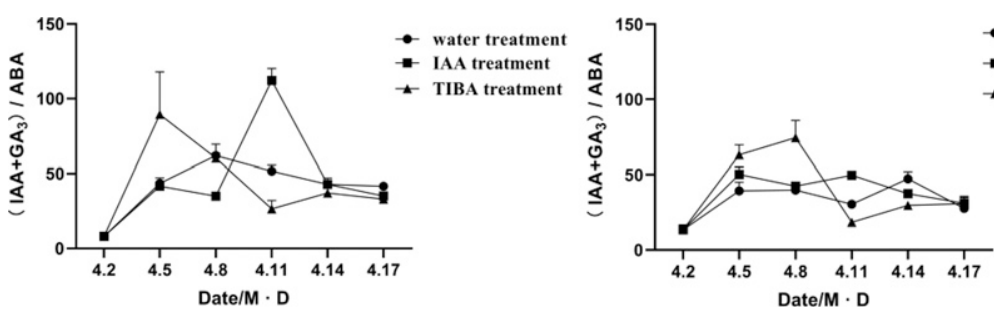

Fig. 12. Effects of different treatments on the [indoleacetic acid (IAA) + gibberellin acid $\left(\mathrm{GA}_{3}\right) / \mathrm{abscisic}$ acid (ABA)] of the calyx tube of 'Korla' fragrant pear. TIBA = triiodobenzoic acid.

endogenous hormones differs from the large flower bud to young fruit stages. The higher mass fraction of IAA in the young fruit and calyxes of 'Korla' fragrant pear was beneficial for the persistence of calyxes (Niu and He, 2009; Qi, 2012). High endogenous IAA and GA concentrations were among the key influencing factors of calyx persistence. The endogenous GA and IAA contents of the young 'Dangshansuli' fruits treated with $\mathrm{GA}_{3}$ increased, and the rate of calyx abscission decreased significantly; the endogenous IAA contents of young 'Dangshan Su' pear fruits treated with $\mathrm{PP}_{333}$ decreased, and the rate of calyx abscission increased significantly (Jia et al., 2012, 2013; Ni and Deng, 1992). These experimental results were consistent with the results of this study during which the IAA, $\mathrm{GA}_{3}$, and $\mathrm{ABA}$ contents of the calyx tubes of 'Korla' fragrant pears exceeded those of the stalks and fleshes from the large flower bud to young fruit stages, and the ABA content of the fourth-order fruits was significantly higher than that of the first-order fruits. The IAA, $\mathrm{GA}_{3}$, and ABA contents of the fleshes of the first- and fourth-order fruits did not significantly differ. The IAA content of the stalks of first-order fruit was significantly greater than that of the fourth-order fruit, whereas the $\mathrm{GA}_{3}$ and ABA contents were not significantly different, indicating that calyxes could persist
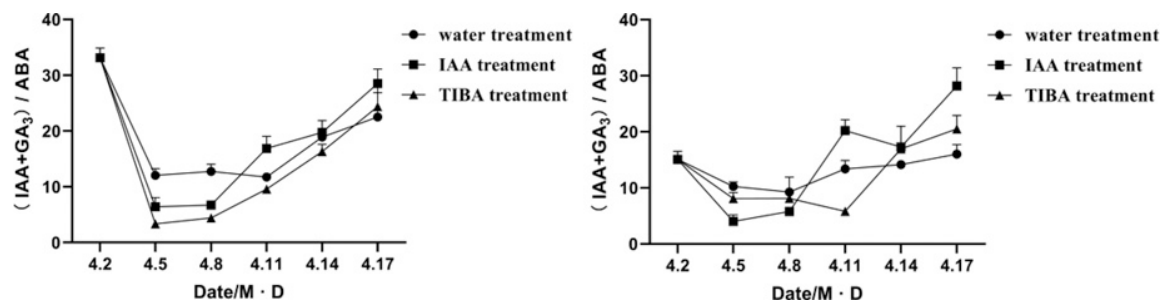

Fig. 13. Effects of different treatments on the [indoleacetic acid (IAA) + gibberellin acid $\left(\mathrm{GA}_{3}\right) / \mathrm{abscisic}$ acid (ABA)] of the flesh of 'Korla' fragrant pear. TIBA = triiodobenzoic acid.
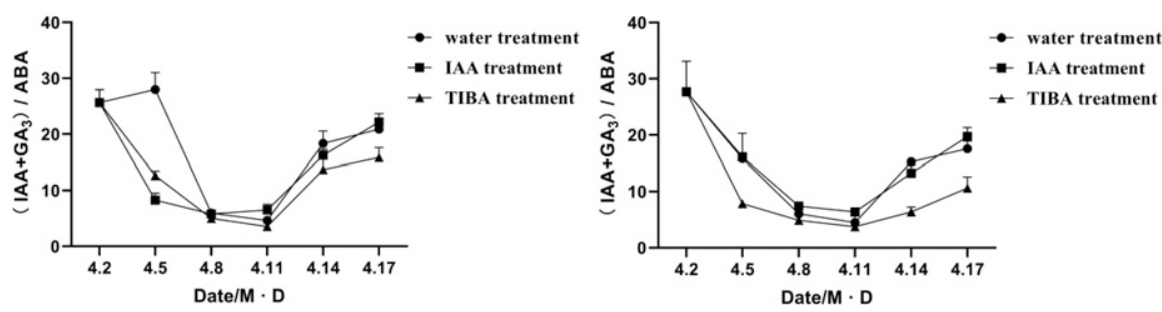

Fig. 14. Effects of different treatments on the [indoleacetic acid (IAA)+ gibberellin acid $\left(\mathrm{GA}_{3}\right) / \mathrm{abscisic}$ acid $(\mathrm{ABA})]$ of the stalks of 'Korla' fragrant pears. TIBA = triiodobenzoic acid. pollen from 'Dangshansuli', 'Yali', 'Xinli 2 ', and 'Zaosuli', and calyx abscission was related to the distribution of endogenous hormones in different parts, which was consistent with the results of this study.

High IAA and $\mathrm{GA}_{3}$ contents in calyxes were beneficial for their persistence, whereas a high ABA content was beneficial for calyx abscission (Cao et al., 2001; Guan et al., 1995; Jiang, 2011; Shi et al., 2018). Higher IAA/ $\mathrm{ABA}, \mathrm{GA}_{3} / \mathrm{ABA}$, and $\left(\mathrm{IAA}+\mathrm{GA}_{3}\right) / \mathrm{ABA}$ ratios benefitted calyx persistence, which was consistent with the results of this study. The results of this experiment indicated that external application of IAA caused an increase in the ratio of $\left(\mathrm{IAA}+\mathrm{GA}_{3}\right) / \mathrm{ABA}$, whereas external application of TIBA caused a decrease in the ratio of $\left(\mathrm{IAA}+\mathrm{GA}_{3}\right) / \mathrm{ABA}$. It was speculated that external IAA application aided calyx persistence, and external application of TIBA aided calyx abscission.

\section{Conclusion}

With higher IAA contents in the calyx tube of 'Korla' fragrant pears, it was more difficult for the sepals to fall off; however, it was easier for the sepals to fall off at higher ABA contents. Spraying IAA during flowering will promote the persistence of sepals, and spraying TIBA will promote sepal shedding. IAA treatment increased the contents of IAA and $\mathrm{GA}_{3}$ in the calyx tube, flesh, and stalk of 'Korla' fragrant pear, and it decreased the content of ABA, thereby inhibiting sepal shedding. TIBA treatment reduced the contents of IAA and $\mathrm{GA}_{3}$ in the calyx tube, flesh, and stalk of 'Korla' fragrant pears, thereby promoting sepal shedding. Different treatments had little effect on the $\left(\mathrm{IAA}+\mathrm{GA}_{3}\right) / \mathrm{ABA}$ ratio of 'Korla' fragrant pear fleshes, and the changes in the endogenous hormone contents of these parts were less notable than those in the other two parts. Additionally, it had little effect on sepal shedding.

\section{Literature Cited}

Cao, S.Y., Y.Q. Tang, and J.C. Zhang. 2001. Effects of $\mathrm{GA}_{3}$ and $\mathrm{PP}_{333}$ on apple flower bud morphogenesis and changes in endogenous hormone ratio. J. Fruit Sci. 18:313-316, https:// doi.org/10.13925/j.cnki.gsxb.2001.06.001.

Chen, J. 2011. The effects of growth regulators on the endogenous hormones, fruit quality and calyx development of Dangshan Su pear young fruit. Anhui Agricultural University.

Duan, N., Y.K. Jia, J. Xu, H.L. Chen, and P. Sun. 2015. Research progress in plant endogenous hormones. J. Chinese Agr. Sci. Bul. 31:159-165.

Gao, J.S., Z.R. Sun, J.L. Wu, X.W. Jiang, and J.J. Feng. 1999. Application effect of paclobutrazol in the flowering period of pear trees. J. Tarim Univ. Agr. Reclamation 11:6-8.

Gong, W.Z., C.Z. Du, J.C. Long, P. Wang, H. Chen, Q. Wang, and J.J. Zhang. 2019. The effect of TIBA on the growth and lodging rate of different shade-tolerant soybean intercropping stage. Soybean Sci. 38:570-575, https://doi.org/ 10.11861.j.issn.1000-9841.2019.04.0570.

Guan, Y.L., A.S. Hu, B.F. Jiang, and L.H. Mou. 1995. Hormonal regulation of citrus fruitshedding. J. Zhejiang Agr. Sci. 7:297-300. 
Han, X.Q. 2018. The role of SIPIN1, SIPIN3, and SIPIN4 in the shedding of tomato flower stalk. Shenyang Agr. University.

He, Z.S., J.X. Niu, and Y.X. Shao. 2006. Summary of the study on the calyx shedding and persistence of 'Korla' fragrant pear fruit. J. Chinese Fruits and Vegetables. 000:10-11.

Huang, M.H., S.H. Feng, S.S. Luo, and W. Li. 2015. Regulating effects of exogenous plant hormones on the quality formation of horticultural products. J. Northern Hort. 12:186-190, https://doi.org/10.11937/bfyy.201512047.

Jia, B., L.W. Zhu, and S.L. Zhang. 2012. Effects of growth regulators on the rate of decalyx fruit, fruit quality and new shoot growth of Dangshan Su pear. J. Nanjing Agr. Univ. 1:26-32.

Jia, S., B. Jia, and L.W. Zhu. 2013. The SSH library construction and EST sequence analysis of the calyx development of Dangshan Su pear. J. Anhui Agr. Univ. 3:454 459, https://doi.org/ 10.13610/j.cnki.1672-352x.2013.03.020.

Jiang, Y.C. 2011. Study on the difference of endogenous hormones and quality between pear calyx shedding and persistent fruits. Nanjing Agr. University.

Jin, M. 2020. Effects of growth regulators on endogenous hormones and PIN genes during the development of 'Korla' fragrant pear sepals. Tarim University. https://doi.org/10.27708/d.cnki. gtlmd.2020.000181.

Li, B.G., L.Z. Mei, and Y.H. Li. 2001. Fruit quality improvement and other management of
'Korla' fragrant pear. Xinjiang Agr. Reclamation Technol. 6:40-42.

Li, L. and X.X. He. 2008. Study on the regulation of plant growth regulators on the calyx shedding and persistence of 'Korla' fragrant pear. J. Xinjiang For. 1:29-30.

Li, C.J., P. Li, C.Z. Jin, J. Tian, Y. Zhang, and J. Li. 2017. The relationship between the distribution of endogenous hormones in young fruit of ' Korla' fragrant pear' and the fall of calyxs from the fruit. J. Northwest Agr. Sci. 26:1631-1638, https://doi. org/10.7606/j.issn.1004-1389.2017.11.009.

Ma, H.C., Y.L. Wang, X. Wen, M. Qi, and L.J. Jiang. 2011. Effects of different chemical treatments on the microstructure of the calyx tube and calyx tube of 'Korla' fragrant pear. J. Fruit Sci. 28:518-520, https://doi.org/10.13925/j.cnki. gsxb.2011.03.027.

Ma, H.Y., S.T. Tao, Y. Chen, R.R. Yu, X.Y. Chen, J.P. Bao, C.Y. Wu, and R. Zhang. 2019. The relationship between the different sequence vascular bundles of the short fruit branches of 'Korla' fragrant pear and calyx shedding. Jiangxi J. Agr. 31:26-30, https://doi.org/10.19386/j.cnki. jxnyxb.2019.04.05.

Ni, D.X. and Z.L. Deng. 1992. The regulation of plant hormones on gene expression. Acta Plant Physiol. 6:67-72, https://doi.org/10.13592/j.cnki. ppj.1992.06.029.

Niu, J.X. and Z.S. He. 2009. Dynamic changes of endogenous hormones in young pear calyx during the process of pear calyx shedding and persistence. J. Fruit Sci. 26:431-434, https://doi.org/10.13925/j.cnki. gsxb.2009.04.030.

Qi, M.F. 2012. Analysis of expression profile of tomato flower stalk shedding-related genes and study on the properties of polygalacturonase. Shenyang Agricultural University.

Qi, X.X. 2014. Analysis of gene expression profile during the persistence and shedding of pear fruit calyxs and preliminary study on the function of PsIDA and PsJOINTLESS genes. Nanjing Agricultural University.

Shao, Y.X. 2007. Summary of plant organ shedding and delamination formation. Modern Agr. Sci. Technol. 9:10-13.

Shi, Z.H., X.Q. Han, Y. Jiang, T. Xu, and T.L. Li. 2018. Effects of SIPIN1 on the shedding of tomato floral organs and the distribution of auxin. J. Shenyang Agr. Univ. 1:1-7, https:// doi.org/10.3969/j.issn.1000-1700.2018.01.001.

Xu, S.L., X.Q. Chen, C.Z. Xu, J.P. Bao, J.B Wang, H. Yang, Z.Y. Xuan, and J. Zhang. 2015. Effects of pollen intuition on the content of endogenous hormones in the young fruit of fragrant pears. China Hort. Abstr. 31:2-15.

Zhou, Y., Y.X. Wu, Y.X. Li, G.Q. Wen, and F. Nie. 2018. Study on the determination of endogenous hormones in blueberry leaves by high performance liquid chromatography. China Fruits 3:88-94, https://doi.org/10.16626/ j.cnki.issn1000-8047.2018.03.023. 